Document downloaded from:

http://hdl.handle.net/10251/68890

This paper must be cited as:

Juan Borras, MDS.; Periche Santamaría, A.; Doménech Antich, EM.; Escriche Roberto, MI. (2015). Correlation between methyl anthranilate level and percentage of pollen in Spanish citrus honey. International Journal of Food Science and Technology. 50(7):1690-1696. doi:10.1111/ijfs.12827.

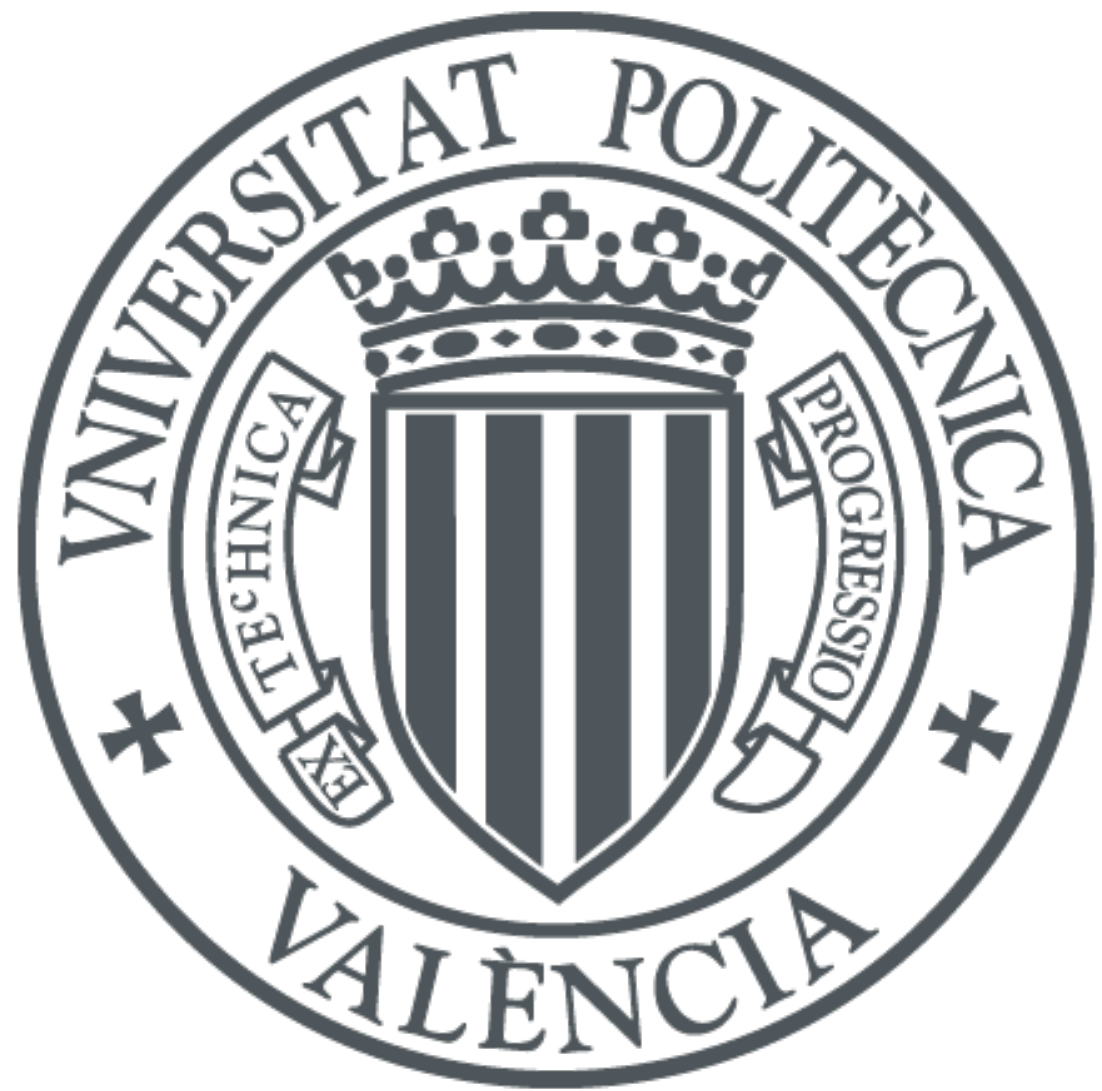

The final publication is available at

https://dx.doi.org/10.1111/ijfs.12827

Copyright Wiley

Additional Information 


\section{Correlation between methyl anthranilate level and percentage of pollen in Spanish} citrus honey

Marisol Juan-Borrás, Angela Periche, Eva Domenech, Isabel Escriche*

Institute of Food Engineering for Development (IUIAD). Food Technology Department

(DTA). Universitat Politècnica de València. P.O. Box 46022 Valencia, Spain.

Corresponding author: Isabel Escriche, iescrich@tal.upv.es

\section{Abstract}

The common level of methyl anthranilate (MA) in Spanish citrus honey and the correlation between this compound and the percentage of citrus pollen (sometimes underrepresented) is evaluated. The MA analysis methodology was validated before analyzing the honeys (harvested in 2011 and 2012), which were characterized by pollen, MA, hydroxymethylfurfural, electrical conductivity, moisture and colour. Pollen ranged $1-88 \%$ and MA $0.5-5.9 \mathrm{mg} / \mathrm{kg}$ and there was no quantitative correlation between both. However, significant correlations with moderate Pearson coefficients were observed: MA/electrical conductivity (-0.678); MA/colour (-0.559); pollen/electrical conductivity $(-0.553)$ and pollen/colour (-0.556). $89.2 \%$ of samples from 2011 and $95.4 \%$ from 2012 had the required level of citrus pollen (at least 10\%), although only $53.5 \%$ and $61.4 \%$, respectively, had the commercially required of MA (2 mg/kg,). Only about half of the samples satisfied both parameters. The MA value should be recommended only when the honey has an unexpectedly low percentage of citrus pollen, and after assessing organoleptic and physicochemical parameters.

Keywords: citrus honey, methyl anthranilate, Citrus spp pollen, correlation, validation, melissopalynological analysis, electrical conductivity, colour 
Traditionally, honey is authenticated by identifying and quantifying the percentage of pollen (Bogdanov, 2002). However, in the case of citrus varieties this melissopalynological analysis alone, widely used for other types of monofloral honey, is sometimes not sufficient. The problem lies in the fact that the production of pollen and nectar in citrus blossom is not always simultaneous. Which is to say that citrus trees sometimes produce nectar before the anther produces pollen. Apart from this, bees occasionally collect nectar from sterile hybrid varieties of citrus trees, which are characterized by their small amounts of pollen. For these reasons the percentage of pollen in citrus honey may be lower than expected (Molins, et al., 1995). This clearly implies a difficulty in relation to the minimum percentage of pollen from Citrus spp. required for this type of honey: 10\% (Persano-Oddo, et al., 1995; Molins et al., 1995; DOGV, 2002); 12\% (Gomez-Pajuelo, 2004); 18.6\% (Persano-Oddo \& Piro, 2004); $\geq 5 \%$ (Rodriguez et al., 2010). This is a problem for the commercialization of this valuable type of honey since it can be unfairly rejected, even though its organoleptic characteristics are undisputed.

Methyl anthranilate (MA) is a specific compound in citrus blossom nectar; its aroma is characteristic of this type of flower (ISO 5496, 2006) which may vary depending on the citrus cultivars (Jabalpurwala, et al., 2009). The presence of this compound in a honey indicates that the bees have taken nectar from citrus trees (White, 1966; White \& Bryant, 1996; Castro-Vazquez, et al., 2007). For this reason, MA has been used for decades as a marker in citrus honey and should be a good tool for the classification of citrus honey when the level of pollen is very low. However, at present, commercial transactions require that citrus honey has a minimum citrus pollen content (between 10 and 20\%), together with a methyl anthranilate level of at least $2 \mathrm{mg} / \mathrm{kg}$ (Sesta, et al., 2008). According to the data reported by different authors, the quantity of MA in the nectar citrus varies, 
53 depending on the country. Citrus honey from Florida has a mean value of $3.10 \mathrm{mg} / \mathrm{kg}$ of 54 MA $(\mathrm{SD}=0.91)($ White \& Bryant, 1996). However, Sesta et al., in 2008 suggested that a minimum content of $0.5 \mathrm{mg} / \mathrm{kg}$ is sufficient for Citrus honey produced in Italy. There are a few old studies related to the level of this aromatic compound in Spanish citrus honey: minimum of $0.5 \mathrm{mg} / \mathrm{kg}$ (Serra-Bonvehí, 1988), and average of $2.3 \mathrm{mg} / \mathrm{kg}(\mathrm{SD}=0.5)$ (Ferreres, et al., 1994; Serra-Bonvehí \& Ventura, 1995). In addition to variation due to geographic origin, levels of MA can differ depending on storage conditions (SerraBonvehí \& Ventura, 1995; White \& Bryant, 1996; Sesta et al, 2008). Therefore, it is important to take this into consideration in order to make appropriate comparisons.

Clearly, there is a great disagreement about the required level of MA in citrus honey. However, the origin of this discrepancy could in part be in the application of different analytical techniques over the last three decades: HPLC-DAD (Ferreres, et al., 1994; Nozal, et al., 2001; Sesta et al, 2008), Photometry (White \& Bryant, 1996), HS-SPMEGC (Bertelli, et al., 2008; Papotti, et al., 2009; Papotti, et al., 2012), P\&T/GC-MS-thermal desorption (Escriche, et al., 2011). As there is no official methodology described for the analysis of MA, the only way to ensure the quality of the obtained results is to validate the quantification methodology.

For the above mentioned reasons, the present work aims to evaluate the level of MA in Spanish citrus honey and to determine the extent to which this level can be related to the percentage of pollen from citrus genus. In order to ensure the utility of the chromatographic procedure used to quantify this compound, it was validated before analyzing the samples.

\section{Material and Methods}

Honey samples 
Ninety eight different samples of Spanish citrus honey were used in this study. The samples were harvested in the only areas (East and South) of Spain where citrus trees grow. The same beekeepers (B) directly supplied twenty eight samples from 2011 and fifty samples in 2012, ensuring that the hives had been located in citrus groves. The remaining twenty samples (10 from 2011 and 10 from 2012) were purchased, in the same period of time, in different retail outlets $(\mathrm{R})$ in the city of Valencia, checking in all cases that they were sold as citrus honey harvested in Spain. A melissopalynological analysis was carried out on all samples to ascertain the percentage of pollen of Citrus spp.

All samples were analysed as soon as they were received in the laboratory. Samples that came from beekeepers were sent to the laboratory immediately after they were harvested. None of the samples used exhibited signs of crystallization.

\section{Melissopalynological analysis}

Pollen analysis was performed using the recommendations of the International Commission for Bee Botany (Ohe, et al., 2004), without an acetolysis solution to preserve all the components. Slides were prepared as follows: $10 \mathrm{~g}$ of honey were dissolved in acidulated water $\left(\mathrm{H}_{2} \mathrm{SO}_{4}, 5 \%\right)$ on a heating plate at $40{ }^{\circ} \mathrm{C}$. Subsequently, it was centrifuged, the supernatant was decanted and the precipitate was suspended in $10 \mathrm{~mL}$ of distilled water. A second centrifugation was performed, the supernatant was decanted off and $0.2 \mathrm{~mL}$ of water was added to the precipitate. After stirring, $0.2 \mathrm{~mL}$ were deposited on a slide and dried. Finally a drop of glycerin was used to seal the coverslip. A light microscope (Zeiss Axio Imager, Göttingen, Germany) with DpxView LE image analysis software attached to a DeltaPix digital camera was used in this analysis. A count of at least 600 pollen grains was performed observing at $\times 400-1000$ magnifications. These grains of pollen were classified according to pollen morphology as in the literature (Carretero, 1989; Saenz-Laín \& Gómez-Ferreras, 2000). 


\section{Methyl anthranilate analysis}

\section{Methodology}

A HPLC-DAD (Diode-Array Detection) method, based on Sesta et al. (2008), was used in the present work for MA determination. The method consists of acid hydrolysis, followed by extraction with copolymer cartridges and then chromatographic analysis. An LC Agilent 1120 Compact LC, including a binary pump, a thermostat column compartment, an auto-sampler and a UV detector were used. The chromatographic column and the software system used in the HPLC-UV method was the same as that used for the HMF analysis.

Chromatographic separation was carried out with a mobile phase consisting of water (A) and acetonitrile (B). Binary gradient conditions were used: first an isocratic step from 0 to 3.1 min with $70 \% \mathrm{~A}$, and then a linear gradient was applied arriving at $42 \% \mathrm{~A}$ in 2 min. After that, a second linear gradient was applied arriving at $10 \% \mathrm{~A}$, held for $2 \mathrm{~min}$, and re-equilibrates to the initial conditions in $3 \mathrm{~min}$. The flow-rate was $1 \mathrm{~mL} / \mathrm{min}$. The injection volume was $20 \mu \mathrm{L}$, and the oven column was maintained at $30^{\circ} \mathrm{C}$. The MA was monitored at $335 \mathrm{~nm}$.

A HPLC Alliance 2695, with a 2996 photodiode array detector (Waters, USA), equipped with the same column, was also used to corroborate the absorbance spectra, necessary for the identification of MA. The UV absorbance spectrum of MA presented an intense absorbance peak at $218 \mathrm{~nm}$ and 2 less intense peaks at 245 and $334 \mathrm{~nm}$. As noted by Sesta et al. (2008), it was considered more appropriate to quantify at the absorbance of $334 \mathrm{~nm}$ as it presents less interference than the other ones.

Under the specified chromatographic conditions the MA peak was eluted at a retention time of about $6.8 \mathrm{~min}$. Quantification was realized by means of matrix calibration curves obtained from spiked fortified blank samples. In order to ensure the quality of the results 
and evaluate the stability of the proposed method, an internal quality control (a spiked blank sample with a final concentration of $2 \mathrm{mg} / \mathrm{kg}$ ) was injected in the equipment as a first step before each batch of sample.

In all cases a polyfloral honey with absence of MA was used as a honey blank. The absence of citrus pollen in this honey was corroborated previously.

\section{Reagents and standards solutions}

HPLC-grade acetonitrile was purchased from VWR and the standard MA (purity > 99\%) from Merck (Darmstadt, Germany). Analytical grade sulphuric acid was from Scharlab (Barcelona, Spain). For Solid Phase Extraction, Oasis HLB cartridges (200 mg/6 $\mathrm{mL)}$ from Waters were used. De-ionized water of MilliQ quality was used throughout.

The stock standard solution of MA was prepared by weighing the appropriate amount of the pure standard and diluting it with water to obtain a final concentration of $1 \mathrm{mg} / \mathrm{mL}$. The working standard solution was obtained at a concentration of $0.1 \mathrm{mg} / \mathrm{mL}$ in $\mathrm{H}_{2} \mathrm{SO}_{4}$ $1 \mathrm{M}$ in the same way as the samples,. The stock standard solution was stored at $-20^{\circ} \mathrm{C}$ and the working standard solution was at $+4^{\circ} \mathrm{C}$.

\section{Validation of the MA analysis method}

The guidelines established by Commission Decision (2002), were followed in order to validate the MA analytical methodology. To this end several parameters were studied: linearity, accuracy and precision (repeatability and reproducibility). The accuracy of the method was established through recovery studies and the precision by: repeatability or intraday precision $\left(\mathrm{RSD}_{\mathrm{r}}\right)$ and reproducibility or interday precision $\left(\mathrm{RSD}_{\mathrm{R}}\right)$. LODs (limit of detection) and LOQs (limit of quantification) were estimated as the amount of analyte for which signal-to-noise ratios $(\mathrm{S} / \mathrm{N})$ were higher than 3 and 10 respectively. 
152 physicochemical parameters (moisture content and electrical conductivity) were analyzed as described in "Harmonized Methods of the European Honey Commission" (Bogdanov, 2002). The chromatographic column used for the analysis of HMF was a ZORBAX Eclipse Plus C18 (4.6 x 150 mm, $5 \mu$ m particle size) purchased from Agilent (Agilent Technologies, USA). The mobile phase for this analysis was water-methanol (90:10, v:v), with a flow rate of $1 \mathrm{~mL} / \mathrm{min}$. The detector was set to $285 \mathrm{~nm}$. The EZChrom Elite system software was used for HPLC data processing. Colour was determined with a millimeter Pfund scale C 221 Honey Color Analyzer (Hanna Instruments, Spain). All analyses were performed in triplicate

\section{Statistical analysis}

The pollen percentage, physicochemical (MA, HMF, electrical conductivity) and colour data were analyzed by a multifactor analysis of variance (ANOVA) (significance level $\alpha=0.05$ ) (using Statgraphics Centurion for Windows) to study the influence of the year of harvesting and the type of sample (beekeeper and retail). The method used for multiple comparisons was the LSD test (least significant difference) with a significance level $\alpha=0.05$. The bivariate Pearson correlations were obtained (significance level $\alpha=$ 0.05 ) in order to measure the strength and direction of the linear relationships between pairs of variables using SPSS 16.0. The contingency table analysis (cross tabulations) was carried out to evaluate the interrelation between pollen and MA, considering these variables as categorical, using the same SPSS 16.0.

\section{Results and Discussion}

Validation of Methyl anthranilate analytical methodology

The results from the validation procedure are shown in Table 1. In order to obtain the linearity evaluation an external standard calibration curve was constructed using spiked 
fortified blank honeys (honeys without MA) with final concentration levels of: $0.5,1,2$,

1773 and $5 \mathrm{mg}$ of MA/kg honey. These concentrations covered the values of this compound

178 which were expected to be found in the honey samples. Six replicates were carried out for each level. Injections were performed in triplicate. A calibration curve was obtained by plotting the peak area of the compound at each level versus the concentration of MA added to the sample. A good linearity response in the range of the concentration considered was observed, with a correlation coefficient $\left(\mathrm{R}^{2}=0.995\right)$ between peak areas and injected nominal concentrations.

The recovery studies were performed by adding known quantities of MA to the blank honey $(0.5,1,2,3$ and $5 \mathrm{mg}$ of $\mathrm{MA} / \mathrm{kg})$. All spiked fortified sample levels were done in triplicate and analyzed by the HPLC method. The results displayed in Table 1 show that the method used led to recovery of MA between 96 and 105\% for the concentration range studied. The relative standard deviation (RSD) corresponding to recovery values ranged from 6.0 to $11.6 \%$. As these values were less than $20 \%$, the accuracy of the analytical method was confirmed (Commission Decision, 2002). fortified honey samples, at the same levels $(0.5,1,2,3$ and $5 \mathrm{mg}$ of MA/kg), and performed by the same operator on the same day. To evaluate reproducibility (RSDR) the experiment was carried out on 3 consecutive days, with 2 different operators. The results were expressed as the percentage of relative standard deviation of the measurements. As shown in Table 1, intra-day precision $\left(\mathrm{RSD}_{\mathrm{r}}\right)$ ranged from $1.40 \%$ to $7.20 \%$ and inter-day precision $\left(\mathrm{RSD}_{\mathrm{R}}\right)$ from $4.50 \%$ to $13.96 \%$. These $\mathrm{RSD}$ values are in complete agreement with Commission Decision (2002), requirements since they were always lower than $20 \%$ for all the concentration levels assayed. Therefore it can be concluded that the method used has good precision. The LOQ obtained was $0.1 \mathrm{mg}$ of MA/kg. 
The results of the validation demonstrate that the applied analytical procedure guarantees satisfactory the quantitative values of MA obtained in the samples analyzed.

203

204

205

206

207

208

209

210

211

212

213

214

215

216

217

Melissopalynological, physicochemical, colour and methyl anthranilate characterization

Table 2 shows the percentage of Citrus spp. pollen, the average values of MA and the physicochemical parameters quantified (HMF, electrical conductivity, and moisture), as well as the colour of each of the samples supplied by beekeepers (B) and purchased in retail outlets (R) in 2011 and in 2012. In addition, this table shows the result (P-value, Fratio and minimum and maximum LSD values) of the multifactor ANOVA carried out considering the factors: year of collection (2011 and 2012) and "type of sample" of citrus honey (beekeepers and retail). The respective double interactions were not significant in any case (data not shown). Fig.1 shows the box and whisker plots for all the values obtained in order to facilitate the comparison of variability patterns between the four sources of citrus honey (beekeepers 2011; beekeepers 2012; retail 2011 and retail 2012).

The citrus pollen percentage varied significantly among type of samples (beekeepers and retail) but not among years of harvesting. This percentage ranged from 1 to 88 (average=34) and from 1 to 69 (average=33) in beekeeper samples from 2011 and 2012, respectively. With regard to the supermarket samples, the pollen percentage ranged from 7 to 40 (average $=18$ ) and from 8 to 42 (average $=19)$, respectively.

Similarly, for MA the biggest dispersion between maximum and minimum corresponds to beekeeper samples $(0.5-4.0 \mathrm{mg} / \mathrm{kg}$ in 2011 and $0.8-5.9 \mathrm{mg} / \mathrm{kg}$ in 2012) with means of 2.1 and $2.4 \mathrm{mg} / \mathrm{kg}$, respectively; whereas the retail samples ranged from 0.6 to $2.9 \mathrm{mg} / \mathrm{kg}(\mathrm{mean}=1.5 \mathrm{mg} / \mathrm{kg})$ for 2011 and from 0.7 to $2.9 \mathrm{mg} / \mathrm{kg}$ (mean= 1.6 $\mathrm{mg} / \mathrm{kg}$ ) for 2012. In general, although not significant differences were observed for MA related to the type of sample, the lowest values and the lowest dispersion for MA (the same as for $\%$ of pollen) were detected, as expected, in retail samples. This is because the 
honey packaging industry mixes the raw honeys to produce relatively homogeneous

227 batches to meet the requirements and specifications that companies have for each type of

228

229

230 monofloral honey such as citrus honey. After reception, these industries analyse the physicochemical properties and pollen of the raw honey in order to discern the characteristics of the raw batches and be able to mix them appropriately.

The HMF of the beekeeper honeys showed relatively low average values $(5.8 \mathrm{mg} / \mathrm{kg}$ for 2011 and $4.1 \mathrm{mg} / \mathrm{kg}$ for 2012). However, unexpectedly high values of 16.5 and 25 $\mathrm{mg} / \mathrm{kg}$ were observed in 2011, probably due to sporadic bad practices. Such high values were not observed in 2012 in any case. As commercialized honeys are usually thermally treated (liquefied and pasteurized) by the industry, the highest values were usually and unsurprisingly found in the retail honeys. It should to be pointed out that one sample exceeded the overall permitted limit of $40 \mathrm{mg} / \mathrm{kg}$ for HMF (Council Directive 2001/110 relating to honey, 2002).

Electrical conductivity was quite low in the majority of the samples, as expected for the type of honeys under consideration (Persano-Oddo \& Piro, 2004; Bogdanov, et al., 2004). The average values were very similar in both types of samples ( 217 and $230 \mu$ S.cm ${ }^{-}$

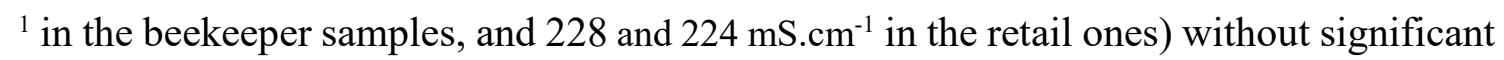
differences neither year nor type of sample.

In the same way no significant differences were found for moisture in relation to both factors, and maximum values did not exceed $19 \mathrm{mg} / 100 \mathrm{~g}$ (Cano, et al., 2001), with one exception of $23.3 \mathrm{mg} / 100 \mathrm{~g}$ (in beekeeper samples of 2012). Beekeeper samples exhibited lower minimum values, reaching $13.1 \mathrm{mg} / 100 \mathrm{~g}$, whereas the minimum value for retail samples was $15.2 \mathrm{mg} / 100 \mathrm{~g}$. Being spring honeys, higher moisture values than those observed could be expected (Serra-Bonvehí, 1988). Again, a lesser dispersion of moisture values, reflecting greater homogeneity, can be seen for retail honey due to processing practices, as mentioned previously. 
On the contrary, with regard to colour, significant differences were found both for year

253

254

255

256

257

258

259

260

261

262

263

264

265

266

267

268

269

270

271

272

273

and supplier factors- Beekeeper samples had lower values, especially those from 2012.

Retail samples reached values of up to $58 \mathrm{~mm}$ Pfund. These higher values could be mainly due to the influence of industrial thermal treatments (liquefaction and pasteurization) (Visquert et al., 2014). Although colour level is not a requirement for citrus honey commercialization, if this honey were sold with a specific quality mark, then particular colour requirements would have to be met. This is the case of the Valencian Quality mark (DOGV, 2002) which requires a maximum of $30 \mathrm{~mm}$ on the Pfund scale to benefit from this Mark. Considering this level, all of the retail samples and more than half of those from beekeepers in 2011 were above it. However, in the case of beekeeper samples from 2012, more than $75 \%$ had values lower than $30 \mathrm{~mm}$ on the Pfund scale.

\section{Relationship between the analysed parameters}

In order to ascertain the possible linear dependence between the analysed variables, Pearson correlation coefficients were calculated for each pair of variables. Only the beekeeper samples were considered in this correlation since the lack of freshness of the retail samples (high HMF values) could have influenced the correlated variables (SerraBonvehí, 1988; Sesta et al., 2008).

Table 3 shows the correlation matrix obtained; the number in brackets is the P-value which tests the statistical significance of the estimated correlations at the $95.0 \%$ confidence level. Although some of the correlations are significant since P-values are below 0.05 , the strength of the linear relationship between each pair of variables is far from the value +1 or -1 . The best correlations are shown for colour and HMF $(0.674$ for 2011 and 0.706 for 2012) and for colour and electrical conductivity (0.596 for 2011 and 0.812 for 2012). The observed correlation between colour and HMF is coherent considering that since from harvesting, honey tends to increase HMF and color naturally as a result of Maillard reactions (Sancho, et al., 1992). The correlation between colour 
and electrical conductivity is widely accepted. In general terms, the darker the honey the higher electrical conductivity. Since the samples considered for this correlation were only the unprocessed honeys, the mineral content was the main cause of this relationship (Bogdanov et al., 2004).

Previous works considered that the MA value could be related to the percentage of pollen and to other specific physicochemical parameters such as moisture and HMF (Serra-Bonvehí, 1988). These authors suggest that MA content decreases with the loss of freshness, with one year old samples showing a lower level of this compound than fresh samples. However no good linear relationship between MA and HMF (-0.375 for 2011 and -0.336 for 2012 ) was observed in this present work. Similarly, there was also no correlation between MA and moisture, despite claims by Serra-Bonvehí (1988) that high moisture content can cause aromatic losses in honey to the point of reducing MA content. It is important to highlight that the range of moistures found in this work was too narrow to draw conclusions about the influence of moisture on this parameter.

In relation to the other physicochemical parameters (electrical conductivity and colour), significant correlations, with moderate Pearson coefficients were observed between them and MA, and pollen, especially for 2012 samples, with values of: MA/electrical conductivity=-0.678; MA/colour=-0.559; pollen/electrical conductivity=0.553 and pollen/colour $=-0.556$. However, on the contrary to what was expected, there was no correlation between MA and the percentage of pollen, the coefficient being 0.347 and 0.253 for samples from 2011 and 2012, respectively.

Once the limited quantitative correlation between MA and the percentage of pollen was demonstrated, it seemed interesting to try to correlate them from a qualitative point of view. Therefore both variables were now considered to be categorical. For this purpose, the samples were classified according to whether they fulfilled the criteria for minimum level of pollen [Citrus spp. pollen higher than 10\%: Molins et al., 1995; Persano-Oddo, 
et al, 1995; DOGV, 2002] and minimum level of MA [2 mg/kg: Persano-Oddo \& Piro, 2004; Sesta et al., 2008 and commercial criteria according to the Spanish industry]. As a consequence, a contingency table was made (only the beekeeper samples were considered since they were always raw samples and not mixed) (Table 4), which is a double entry constructed by listing the variable "pollen" as rows and the variable "MA" as columns. Each variable has only two levels: comply or not comply. Each cell in the table represents the percentage of samples that satisfy the criterion of the row (\% of Citrus spp pollen) or the column (MA concentration), both (\% pollen and MA) or neither. Of all the observations, $89.2 \%$ (in 2011) and 95.4\% (in 2012) comply with the pollen requirement (at least 10\% citrus pollen) for a Mark of Quality (e.g. the Valencian Quality Mark: DOGV, 2002). In the case of methyl anthranilate the percentage of compliance (at least 2 $\mathrm{mg} / \mathrm{kg}$ ) was 53.5 and $61.4 \%$, respectively. As mentioned above, in the case of citrus varieties, in addition to pollen, the methyl anthranilate content is required for commercial transactions, as was suggested several years ago by some European laboratories (Sesta et al., 2008).

In this work, $53.5 \%$ for 2011 and $56.8 \%$ for 2012 of the samples fulfilled both \% pollen and MA concentration. On the other hand, $35.7 \%$ and $38.6 \%$ of the samples met $\%$ pollen but not MA, and $4.6 \%$ of the samples from 2012 complied with MA but not $\%$ pollen. Finally, $10.8 \%$ of samples from 2011 met neither $\%$ pollen nor MA.

It does not seem logical that MA, a parameter that has been proposed to complement the information given by pollen in citrus honeys when pollen is under-represented, is actually an impediment to its classification. The way that MA is being applied does not seem to help this purpose. In fact, if melissopalynological analysis alone were considered in this study, as in other types of monofloral honey, $89.2 \%$ of samples from 2011 and 95.4\% from 2012 would be accepted. However, $35.7 \%$ and $38.6 \%$ of the samples, 
respectively, which complied with the pollen requirement would be rejected commercially for not reaching $2 \mathrm{mg} / \mathrm{kg}$ for MA.

According to the results obtained, the criterion of $2 \mathrm{mg} / \mathrm{kg}$ for MA seems to be too demanding, and therefore not suitable for Spanish citrus honeys. Studies carried out by other authors on this type of honey from Spain and Italy (Sesta et al., 2008; Papotti et al., 2009), concluded that MA content was usually lower than the commercial requirement of $2 \mathrm{mg} / \mathrm{kg}$. This fact was demonstrated even in honeys which obviously had the sensory characteristics of this type of honey. Maybe, for these Mediterranean countries it would be appropriate to propose a lower value than is expected in other parts of the world (White \& Bryant, 1996). According to the results, it seems more appropriate to only demand this value in the case of honeys with an unexpectedly low percentage of citrus pollen. That is, honeys with the typical physicochemical and sensory characteristics of citrus honey (light amber colour, evident notes of acidity and a very unique flavour due to the presence of specific aromatic substances) but without sufficient citrus pollen for this type of honey (Escriche, et al., 2011).

\section{Conclusions}

The results showed that there was a very weak linear correlation between the level of methyl anthranilate and the percentage of pollen in the samples analysed. In almost half of the cases the quantity of MA in Spanish citrus honey was lower than the commercial requirement, which was also reported by other authors for Italian citrus honey. This occurs even though the honeys have a more than sufficient commercial level of citrus pollen. This paper proposes reconsidering the level of MA required in Spanish citrus honey and applying a more realistic value. But above all, to only take this parameter into account in the case of honeys with a surprisingly low percentage of citrus pollen, and after evaluating their organoleptic and physicochemical properties. 


\section{Acknowledgment}

355 This study forms part of a project funded by the company Melazahar Cooperativa

356 Valenciana (Spain), with the title of "Idoneidad del metilantranilato en la clasificación de 357 mieles de azahar (UPV: 27115)" for which the authors are grateful.

\section{References}

Bertelli, D., Papotti, G., Lolli, M., Sabatini, A.G. \& Plessi, M. (2008). Development of an HS_SPME_GC method to determine the methyl anthranilate in Citrus honey. Food Chemistry, 108, 297-303.

Bogdanov, S. (2002). Harmonized methods of the International Honey Commission. Swiss Bee Research Centre, FAM, Liebefeld, CH 3003 Bern, Switzerland.

Bogdanov, S., Ruoff, K. \& Persano-Oddo, L. (2004). Physico-chemical methods for the characterization of unifloral honeys: a review. Apidologie, 35, 4-17.

Cano, C. B., Felsner, M. L., Matos, J. R., Bruns, R. E, Whatanabe, H. M. \& AlmeidaMuradian, L. B. (2001). Comparison of Methods for Determining Moisture Content of Citrus and Eucalyptus Brazilian Honeys by Refractometry. Journal of Food Composition and Analysis, 14, 101-109.

Carretero, J. L. (1989). Análisis polínico de la miel (1st ed.). Multi-Prensa, Madrid, España.

Castro-Vazquez, L., Diaz-Maroto, M.C. \& Pérez-Coello, M.S. (2007). Aroma composition and new chemical markers of Spanish citrus honeys. Food Chemistry, 103, 601-606.

Commission Decision 2002/657/EC of 12 August (2002). Implementing Council Directive 96/23/EC concerning the performance of analytical methods and the interpretation of results, OJEC L221, 8-36. Brusels, Belgium.

Council Directive 2001/110 relating to honey (2002). Official Journal of the European 
381

382

383

384

DOGV (Valencian Region Regulation) No. 4167 (2002). Reglamento de la Marca de Calidad CV para miel de azahar y romero, in: Diario Oficial de la Generalitat Valenciana. Área de publicaciones de la Presidencia de la Generalitat Publishing.

Escriche, I., Kadar, M., Juan-Borrás, M. \& Domenech, E. (2011). Using flavonoids, phenolic compounds and headspace volatile profile for botanical authentication of lemon and orange honeys. Food Research International, 44 (5), 1504-1513.

Ferreres, F., Giner, J.M. \& Tomás-Barberán, F.A. (1994). A comparative study of hesperetin and methyl anthranilate as markers of the floral origin of citrus honey, Journal of the Science of Food and Agriculture, 65, 371-372.

Gomez-Pajuelo, A. (2004). Origen botánico de la miel, In: Montagud S.A (Ed). Mieles de España y Portugal (pp. 50-56). Barcelona, Spain.

ISO 5496 (2006). Sensory Analysis. Methodology. Initiation and training of assessors in the detection and recognition of odours.

Jabalpurwala, F.A., Smoot, J. M., Rouseff, R. L. (2009). A comparison of citrus blossom volatiles. Phytochemistry, 70, 1428-1434.

Molins, J.L., Perea, F., Montilla, J., Martinez, E. \& Guerra, E. (1995). Characterization du miel d'orange (Citrus sp.) produit en Espagne, au moyen de son spectre pollinique. Lagascalia, 18, 71-82.

Nozal, M., Bernal, J., Toribio, L., Jiménez, J.J. \& Martín, M.T. (2001). High-performance liquid chromatographic determination of methyl anthranilate, hydroxymethylfurfural and related compounds in honey. Journal of Chromatography A, 917, 95-103.

Ohe, W., Persano-Oddo, L., Piana, M.L., Morlot, M. \& Martin, P. (2004). Harmonized methods of melissopalynology. Apidologie, 35, 18-25. 
Papotti, G., Bertelli, D., Lolli, M., Sabatini, A.G. \& Plessi M. (2009). Methyl anthranilate content in italian citrus honeys determined by HS-SPME-GC. International Journal of Food Science and Technology, 44, 1933-1938.

Papotti, G., Bertelli, D. \& Plessi, M. (2012). Use of HS-SPME-GC-MS for the classification of Italian lemon, orange and citrus spp. Honeys. International Journal of Food Science and Technology, 47, 2352 -2358.

Persano-Oddo L., Piazza M.G., Sabatini A.G. \& Accorti M. (1995). Characterization of unifloral honeys. Apidologie, 26, 453-465.

Persano-Oddo, L. \& Piro, R. (2004). Main European unifloral honeys: descriptive sheets. Apidologie, 35, S38-S81.

Rodriguez, I., Serrano, S., Galán, H., Ubera, J.L., \& Jodral, M. (2010). Characterisation of Sierra Morena citrus blossom honey (Citrus sp). International Journal of Food Science and Technology, 45, 2008-2015.

Saenz-Laín, C. \& Gómez-Ferreras, C. (2000). Mieles españolas. Características e identificación mediante el análisis del polen. (1st ed.). Multi-Prensa, Madrid, España.

Sancho, M.T., Muniategui, S., Huidobro, J.F. \& Simal, J. (1992). Aging of honey. Journal of Agricultural and Food Chemistry, 40, 134-138.

Serra-Bonvehí, J. (1988). Determinación de antranilato de metilo en la miel de citricos (Citrus sp.) del Levante Español, y su influencia en la actividad diastásica de la miel. Alimentaria, 197, 37-40.

Serra-Bonvehí, J. \& Ventura, F. (1995). Characterization of Citrus honey produced in Spain. Journal of Agricultural and Food Chemistry, 43, 2053-2057.

Sesta, G., Piana, M.L., Persano-Oddo, L., Lusco, L. \& Belligoli, P. (2008). Methyl anthranilate in Citrus honey. Analytical method and suitability as a chemical marker. Apidologie, 39, 334-342. 
429 Visquert, M., Vargas, M., \& Escriche, I. (2014). Effect of postharvest storage conditions 430 on the colour and freshness parameters of raw honey. International Journal of Food $431 \quad$ Science and Technology, 49, 181-187.

432 White, J. W. (1966). Methyl anthranilate content of citrus honeys. Journal of Food 433 Science, 31, 102-104.

434 White J.W. \& Bryant V.M. (1996). Assessing Citrus honey quality: pollen and methyl 435 anthranilate content. Journal of Agricultural and Food Chemistry, 44, 3423-3425.

\section{FIGURE CAPTIONS}

437 Fig. 1. Box \& whisker plots for pollen, MA, HMF, electrical conductivity, moisture and 438 colour for honeys from the beekeepers (B) and retail outlets (R). Samples harvested in $439 \quad 2011$ and in 2012. 
$\%$ Citrus pollen

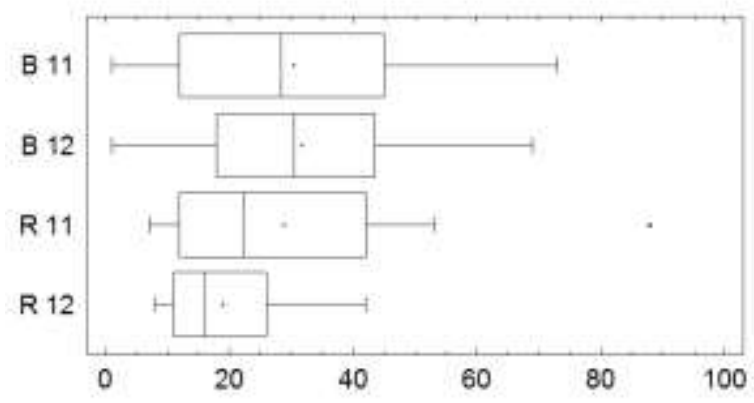

$\mathrm{HMF}(\mathrm{mg} / \mathrm{kg})$

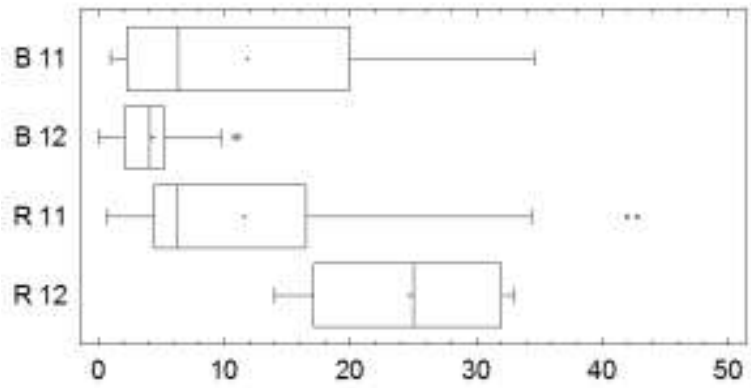

Moisture $(g / 100 g)$

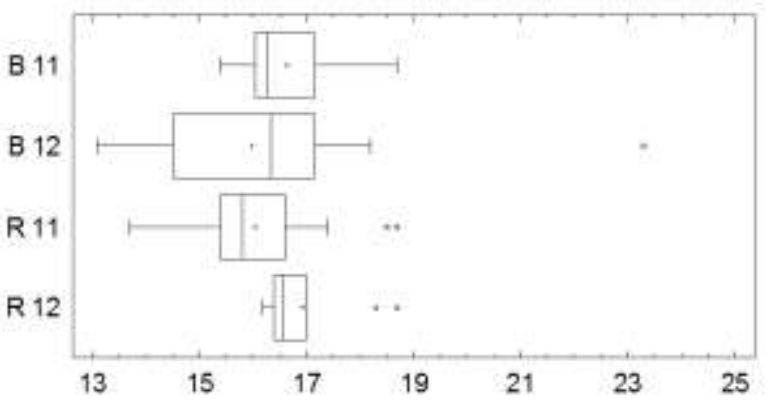

Methyl anthranilate $(\mathrm{mg} / \mathrm{kg})$
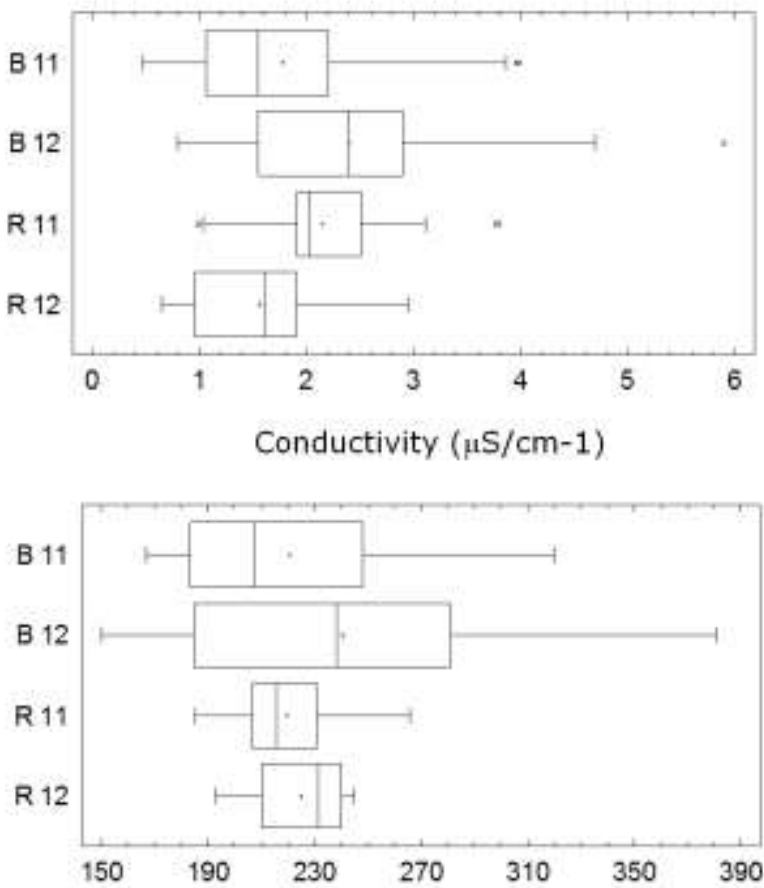

Colour (mmPfund)

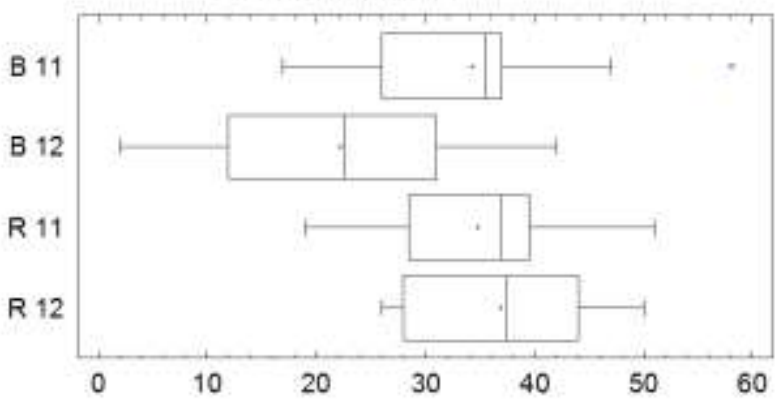

442

443

444

445

446

447 
Table 1. Validation parameters (accuracy and precision) of methyl anthranilate (MA) methodology. The numbers in brackets are the relative standard deviation. Six replicates were carried out for each level.

\begin{tabular}{cccc}
\hline & & Intra-day-precision & Inter-day-precision \\
\cline { 3 - 4 } $\begin{array}{c}\text { MA Added } \\
(\mathrm{mg} / \mathrm{kg})\end{array}$ & $\begin{array}{c}\text { Mean Recovery } \\
\mathrm{RSD}(\%)\end{array}$ & $\begin{array}{c}\text { Mean value }(\mathrm{mg} / \mathrm{kg}) \\
\mathrm{RSD}_{\mathrm{r}}(\%)\end{array}$ & $\begin{array}{c}\text { Mean value }(\mathrm{mg} / \mathrm{kg}) \\
\mathrm{RSD}_{\mathrm{R}}(\%)\end{array}$ \\
\hline 0.5 & $96.0(6.0)$ & $0.50(4.10)$ & $0.49(12.00)$ \\
1.0 & $105.0(6.5)$ & $1.08(7.20)$ & $1.03(5.80)$ \\
2.0 & $104.0(10.8)$ & $2.10(4.11)$ & $2.06(13.96)$ \\
3.0 & $99.0(11.6)$ & $2.63(4.02)$ & $2.36(13.70)$ \\
5.0 & $100.0(6.4)$ & $5.06(1.40)$ & $5.05(4.50)$ \\
\hline
\end{tabular}


Table 2. Percentage of Citrus spp. pollen, average values $(n=3)$ of methyl anthranilate (MA) and physicochemical parameters (HMF, electrical conductivity, moisture) and the colour of each of the samples supplied by beekeepers (B) (28 from 2011 and 50 from 2012) and purchased in retail outlets (R) (10 from 2011 and 10 from 2012). Average and standard deviation (in brackets) for each parameter. Multifactor ANOVA results (P-value, F-ratio, minimum and maximum LSD values) obtained for the factors: year (2011 and 2012) and sample (beekeepers and retail).

\begin{tabular}{|c|c|c|c|c|c|c|c|c|c|c|c|c|}
\hline \multirow[b]{2}{*}{ Samples } & \multicolumn{2}{|c|}{$\begin{array}{l}\text { \%Pollen } \\
\text { Citrus spp }\end{array}$} & \multicolumn{2}{|c|}{$\begin{array}{c}\text { MA } \\
(\mathrm{mg} / \mathrm{kg})\end{array}$} & \multicolumn{2}{|c|}{$\begin{array}{c}\text { HMF } \\
(\mathrm{mg} / \mathrm{kg})\end{array}$} & \multicolumn{2}{|c|}{$\begin{array}{c}\text { Electrical } \\
\text { conductivity } \\
\left(\mu \mathrm{S} . \mathrm{cm}^{-1}\right)\end{array}$} & \multicolumn{2}{|c|}{$\begin{array}{c}\text { Moisture } \\
\text { (mg/100g) }\end{array}$} & \multicolumn{2}{|c|}{$\begin{array}{c}\text { Colour } \\
\text { mm Pfund }\end{array}$} \\
\hline & 2011 & 2012 & 2011 & 2012 & 2011 & 2012 & 2011 & 2012 & 2011 & 2012 & 2011 & 2012 \\
\hline B01 & 48 & 35 & 1.9 & 1.4 & 5.1 & 1.2 & 264 & 167 & 15.4 & 15.4 & 36 & 2 \\
\hline B02 & 42 & 48 & 3.2 & 2.5 & 1.1 & 0.5 & 183 & 150 & 15.5 & 16.7 & 28 & 3 \\
\hline B03 & 73 & 47 & 2.1 & 3.6 & 4.0 & 1.4 & 241 & 161 & 16.2 & 14.5 & 37 & 5 \\
\hline B04 & 48 & 40 & 1.2 & 3.3 & 3.7 & 1.7 & 243 & 157 & 17.9 & 17.8 & 27 & 6 \\
\hline B05 & 36 & 68 & 1.3 & 3.5 & 1.7 & 1.6 & 167 & 163 & 15.5 & 17.2 & 17 & 6 \\
\hline B06 & 1 & 47 & 0.5 & 4.5 & 11.8 & 1.6 & 283 & 164 & 16.8 & 16.4 & 37 & 7 \\
\hline B07 & 5 & 46 & 1.3 & 3.3 & 7.6 & 1.5 & 248 & 167 & 16.2 & 18.0 & 32 & 9 \\
\hline B08 & 30 & 69 & 0.9 & 3.5 & 9.4 & 2.0 & 271 & 169 & 15.8 & 17.4 & 43 & 11 \\
\hline B09 & 27 & 4 & 1.5 & 4.7 & 3.8 & 1.5 & 208 & 187 & 16.3 & 14.5 & 35 & 11 \\
\hline B10 & 63 & 48 & 3.8 & 5.9 & 1.7 & 1.1 & 167 & 161 & 18.6 & 18.2 & 20 & 11 \\
\hline B11 & 57 & 60 & 4.0 & 2.5 & 1.5 & 2.6 & 172 & 170 & 17.8 & 16.3 & 20 & 11 \\
\hline B12 & 33 & 37 & 2.2 & 1.1 & 1.5 & 0.7 & 194 & 233 & 17.2 & 15.9 & 22 & 19 \\
\hline B13 & 42 & 37 & 2.2 & 2.9 & 2.4 & 4.3 & 198 & 183 & 16.7 & 18.0 & 26 & 13 \\
\hline B14 & 46 & 23 & 2.5 & 2.2 & 3.2 & 2.6 & 189 & 210 & 16.6 & 14.3 & 19 & 18 \\
\hline B15 & 12 & 48 & 1.9 & 2.9 & 16.5 & 4.6 & 205 & 188 & 16.6 & 16.9 & 33 & 14 \\
\hline B16 & 36 & 1 & 2.1 & 3.6 & 7.9 & 2.2 & 202 & 254 & 16.5 & 14.8 & 25 & 16 \\
\hline B17 & 43 & 37 & 2.2 & 2.6 & 5.4 & 3.8 & 185 & 207 & 17.3 & 14.0 & 22 & 18 \\
\hline B18 & 88 & 30 & 1.3 & 1.6 & 25.0 & 3.0 & 212 & 290 & 16.3 & 13.2 & 35 & 20 \\
\hline B19 & 53 & 65 & 3.8 & 2.4 & 3.8 & 3.9 & 208 & 233 & 15.4 & 16.1 & 24 & 20 \\
\hline B20 & 8 & 12 & 1.1 & 1.5 & 5.6 & 7.1 & 215 & 238 & 16.0 & 17.1 & 33 & 21 \\
\hline B21 & 19 & 42 & 1.9 & 2.3 & 8.7 & 4.5 & 210 & 246 & 14.8 & 23.3 & 39 & 21 \\
\hline B22 & 11 & 35 & 2.9 & 2.3 & 7.6 & 5.2 & 228 & 222 & 15.8 & 16.7 & 37 & 22 \\
\hline B23 & 35 & 10 & 2.1 & 1.9 & 6.8 & 3.9 & 209 & 288 & 13.8 & 13.3 & 37 & 23 \\
\hline B24 & 17 & 20 & 1.9 & 2.9 & 4.6 & 4.9 & 266 & 239 & 16.6 & 14.5 & 40 & 24 \\
\hline B25 & 10 & 45 & 2.4 & 1.6 & 0.7 & 4.2 & 169 & 259 & 17.8 & 13.3 & 20 & 24 \\
\hline B26 & 42 & 26 & 1.9 & 1.7 & 4.9 & 2.8 & 233 & 273 & 18.6 & 14.7 & 32 & 25 \\
\hline B27 & 14 & 20 & 2.2 & 2.7 & 4.8 & 7.9 & 255 & 258 & 15.4 & 16.8 & 40 & 27 \\
\hline B28 & 12 & 28 & 2.7 & 0.8 & 0.9 & 5.3 & 220 & 312 & 15.6 & 14.4 & 37 & 27 \\
\hline B29 & & 30 & & 2.5 & & 11.1 & & 241 & & 17.2 & & 27 \\
\hline B30 & & 19 & & 1.4 & & 4.1 & & 332 & & 13.3 & & 29 \\
\hline B31 & & 27 & & 2.0 & & 5.2 & & 273 & & 13.8 & & 29 \\
\hline B32 & & 34 & & 1.3 & & 4.3 & & 278 & & 13.6 & & 29 \\
\hline
\end{tabular}




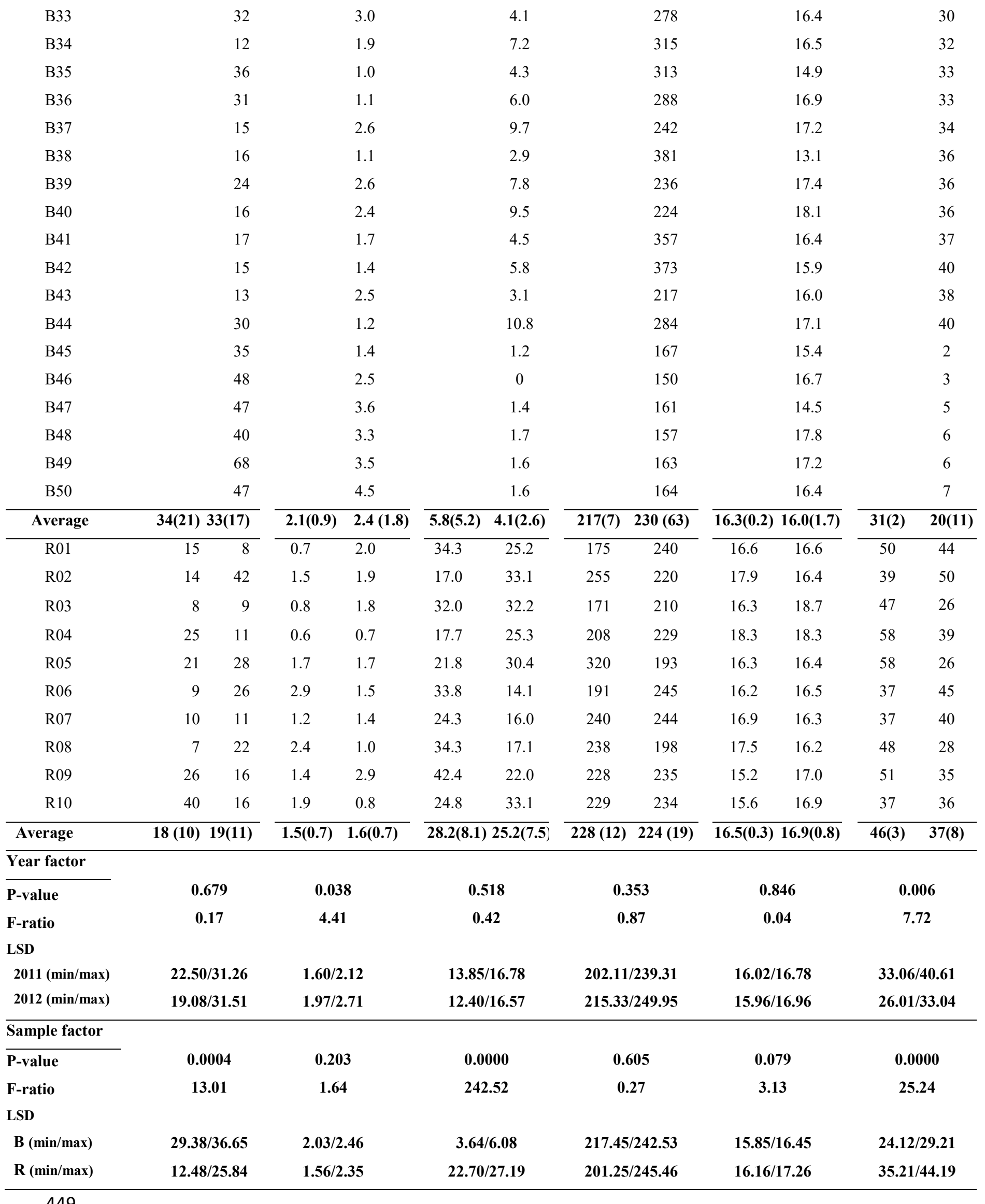


Table 3. Correlation matrix (Pearson correlation coefficients) between percentage of pollen (Citrus spp), methyl anthranilate (MA), HMF, moisture, electrical conductivity and colour. Samples harvested in 2011 and 2012.

\begin{tabular}{|c|c|c|c|c|c|c|c|c|c|c|}
\hline & Po & & $\mathbf{M}$ & & & & & isture & $\begin{array}{r}\text { Ele } \\
\text { cond }\end{array}$ & $\begin{array}{l}\text { ctrical } \\
\text { uctivity }\end{array}$ \\
\hline & 2011 & 2012 & 2011 & 2012 & 2011 & 2012 & 2011 & 2012 & 2011 & 2012 \\
\hline MA (mg/kg) & 0.347 & 0.253 & & & & & & & & \\
\hline & $(0.062)$ & $(0.098)$ & & & & & & & & \\
\hline$\overline{\mathrm{HMF}(\mathrm{mg} / \mathrm{kg})}$ & -0.292 & -0.380 & -0.375 & -0.336 & & & & & & \\
\hline & $(0.011)$ & $(0.011)$ & $(0.001)$ & $(0.026)$ & & & & & & \\
\hline Moisture (g/100g) & 0.090 & 0.285 & 0.037 & 0.303 & -0.069 & 0.200 & & & & \\
\hline & $(0.437)$ & $(0.061)$ & $(0.754)$ & $(0.046)$ & $(0.556)$ & $(0.194)$ & & & & \\
\hline Electrical conductivity & -0.213 & -0.553 & -0.334 & -0.678 & 0.101 & 0.413 & -0.132 & -0.352 & & \\
\hline$\left(\mu \mathrm{S} / \mathrm{cm}^{-1}\right)$ & $(0.065)$ & $(0.000)$ & $(0.003)$ & $(0.000)$ & $(0.386)$ & $(0.005)$ & $(0.255)$ & $(0.019)$ & & \\
\hline Pfund colour (mm) & -0.401 & -0.556 & -0.519 & -0.559 & 0.674 & 0.706 & -0.189 & -0.107 & 0.596 & 0.812 \\
\hline & $(0.003)$ & $(0.000)$ & $(0.000)$ & $(0.000)$ & $(0.000)$ & $(0.000)$ & $(0.102)$ & $(0.491)$ & $(0.000)$ & $(0.000)$ \\
\hline
\end{tabular}

Numbers in brackets $=$ P-value 
Table 4. Contingency table for pollen (comply with 10\% of Citrus spp pollen) and MA (comply with $2 \mathrm{mg} / \mathrm{kg}$ ). Samples harvested in 2011 and 2012.

\begin{tabular}{|c|c|c|c|c|c|c|}
\hline & \multicolumn{2}{|c|}{$\begin{array}{l}\text { Comply with } \\
\mathrm{MA} \geq 2 \mathrm{mg} / \mathrm{kg}\end{array}$} & \multicolumn{2}{|c|}{$\begin{array}{l}\text { Not comply } \\
\text { MA } \geq 2 \mathrm{mg} / \mathrm{kg}\end{array}$} & \multicolumn{2}{|c|}{ Total } \\
\hline & 2011 & 2012 & 2011 & 2012 & 2011 & 2012 \\
\hline $\begin{array}{l}\text { Comply with } \\
\text { pollen } \geq \mathbf{1 0 \%} \\
\text { Citrus spp }\end{array}$ & $53.5 \%$ & $56.8 \%$ & $35.7 \%$ & $38.6 \%$ & $89.2 \%$ & $95.4 \%$ \\
\hline $\begin{array}{l}\text { Not comply with } \\
\text { pollen } \geq \mathbf{1 0 \%} \\
\text { Citrus spp }\end{array}$ & $0 \%$ & $4.6 \%$ & $10.8 \%$ & $0 \%$ & $10.8 \%$ & $4.6 \%$ \\
\hline Total & $53.5 \%$ & $61.4 \%$ & $46.5 \%$ & $38.6 \%$ & $100.0 \%$ & $100.0 \%$ \\
\hline
\end{tabular}

451

452

453

454

455

456

457

458

459

460

461

462

463 